\title{
The Role of Pro-Organizational Motivation as Antecedent of Job Crafting: A Qualitative Exploration
}

\author{
Domenico Berdicchia ${ }^{1} \&$ Giovanni Masino ${ }^{1}$ \\ ${ }^{1}$ Department of Economics and Management, University of Ferrara, Ferrara, Italy \\ Correspondence: Domenico Berdicchia, Department of Economics and Management, University of Ferrara, Via \\ Voltapaletto 11, Ferrara, Italy. E-mail: domenico.berdicchia@unife.it
}

Received: July 20, 2020

Accepted: September 1, 2020

Online Published: September 16, 2020

doi:10.5539/ijbm.v15n10p1

URL: https://doi.org/10.5539/ijbm.v15n10p1

\begin{abstract}
The concept of "job crafting" is one of the most interesting constructs within the organizational literature about proactivity in the workplace. Several authors pointed out the need of longitudinal research on job crafting. In this paper we illustrate the results of a qualitative empirical research conducted within a large retail company. While available job crafting theory emphasizes individual goals as key motivational drivers for job crafting, we found that organizationally oriented goals and motivations are also very relevant. We also found that when a convergence of individual and organizational goals is observed, the motivation towards job crafting is significantly increased, and that work experience plays a significant role in such process.
\end{abstract}

Keywords: job crafting, pro-organizational motivation, proactivity, experience, qualitative

\section{Introduction}

Classic job design theories like Job Characteristic Theory (Hackman \& Oldham, 1980) and Socio-Technical Theory (Emery \& Trist, 1960; Pasmore, 1995) portray job design as a managerial prerogative. Managers define job requirements and boundaries, while employees act as passive recipients. Even classic motivational theories (Maslow, 1954; McClelland, 1971; Vroom, 1964), while shifting the focus on psychological mechanisms, "still afforded a backseat role to conscious intentions, motives and desires, as they portrayed employees as passively evaluating and selecting among the options that managers provided" (Grant \& Ashford, 2008, p. 6).

In the last few years, however, scholars have devoted increasing attention to the concept of workers' "proactivity", in which a more participatory vision of job (co)-design is introduced (Letona-Ibanez, Carrasco, Martinez-Rodriguez, Amillano, \& Ortiz-Marques, 2019). The concept of job crafting is the most studied proactive behavior, especially in relation to its positive effects in terms of person-job fit ( $\mathrm{Lu}, \mathrm{Wang}, \mathrm{Lu}, \mathrm{Du}, \&$ Bakker, 2014), individual well-being (Tims, Bakker, \& Derks, 2013), work engagement (Bakker, Tims, \& Derks, 2012).

It is not surprising that scholars are increasing their efforts to investigate the conditions that facilitate job crafting (Zhang, \& Parker, 2019). However, our understanding of job crafting still needs to be improved, especially because most research methods that have been used to study it are based on an essentially static approach. Most theoretical models hypothesize relationships between variables without considering that they can change over time, as the work process unfolds in ways that simple observational "snapshots" cannot fully capture. Indeed, several prominent job crafting scholars called for more time-centered, longitudinal, qualitative research (Grant \& Ashford, 2008; Nicholson, 2010; Wrzesniewski \& Dutton, 2001; Yitzhak, Grant, Levi, Hadani, \& Haynes Slowick, 2007; Zhang, \& Parker, 2019), because such research approach may help capturing the specific experiences and thoughts of individuals within their situational context (Lazazzara, Tims, \& de Gennaro, 2020). In this paper we take on such calls for a more process-oriented research. We studied the role of pro-organizational motivation in encouraging job crafting behaviors. Since the seminal contribution by Wrzesniewski and Dutton (2001), job crafting motivation have been extensively explored - for a recent metareview see Rudolph, Katz, Lavigne, and Zacher (2017) or Zhang and Parker (2019). However, the main focus of most studies has been on self-oriented motivations for job crafting, while pro-social and pro-organizational aspects have been largely neglected. Our study contributes to fill such literature gap. We adopt a time-dependent view of people's behavior in the workplace in order to unveil some of the job crafting's intricacies that might be neglected by more static research approaches. 


\section{Motivation for Job Crafting}

In their original contribution, Wrzesniewski and Dutton (2001) defined job crafting as "the physical and cognitive changes individuals make in the task or relational boundaries of their work" (Wrzesniewski \& Dutton, 2001, p. 179). There are three major types of job crafting practices (Wrzesniewski \& Dutton, 2001): i) changing task boundaries (altering number, type and/or nature of tasks); ii) changing relational boundaries (altering number, type and/or nature of relationship with others like colleagues, managers, customers, etc.); iii) changing cognitive task boundaries (changing how work is perceived and interpreted by the worker himself / herself).

The original job crafting model includes three main motivations explaining why workers act as job crafters: i) the need for control; ii) the need for a positive self-image; iii) the need for human connections. Thus, job crafters' motivations are clearly located at the individual level of analysis. Wrzesniewski and Dutton (2001) explicitly emphasize that the difference between job crafting and other proactivity constructs, such as personal initiative (Frese, Kring, Soose, \& Zempel, 1996), role innovation (Schein, 1971), role making (Graen \& Scandura, 1987), organizational citizenship (Organ, 1997) and task revision (Staw \& Boettger, 1990), is mostly dependent on the fact that job crafting is not concerned with organizational problem solving or task accomplishment.

Other job crafting models have been proposed. One of the most utilized is conceptualized within the Job Demands - Resources framework (Tims \& Bakker, 2010), according to which workers craft their jobs by changing their job resources and demands in order to develop their abilities according to their preferences, values and goals. This conceptual model also implies that pro-self motivations represent the key drivers for behaviors and initiatives aimed at proactively changing one's job: "the changes that job crafters make are primarily aimed at improving their person-job fit and work motivation" (Tims, Bakker, \& Derks, 2012, p. 174).

Recently, research on job crafting motivations has been extended. For example, Niessen, Weseler, and Kostova (2016) found that an increase in job crafting at Time 2 was predicted by need for positive self-image (Time 1), and that the need for human connection (Time 1) was related to job crafting at Time 2 when self-efficacy was high. Moon, Youn, Hur, and Kim (2018) found that spirituality is positively related to employee's intrinsic motivation, which in turn results in engagement in job crafting. Shin and Jung (2019) found that autonomous extrinsic motivation and intrinsic motivation predict job crafting. Laurence, Fried, Yan, and Li (2020) show the relevance of a specific kind of intrinsic motivation (enjoyment of work) as an antecedent of job crafting.

However, while available studies confirm the relevance of individual, intrinsic motivation for job crafting, pro-organizational motivations have not been addressed as a possible antecedent. In proactivity literature it is recognized that pro-self, pro-social and pro-organizational motives are all important elements in order to explain proactive behaviors (Belschak \& Den Hartog, 2010). Also, a recent metareview on job crafting underlined that such motivations, although under-explored, may constitute a significant antecedent (Lazazzara et al., 2020).

We can define pro-social motivation as the desire to take action that benefits others (Batson, Ahmad, Powell, \& Stocks, 2008); pro-organizational motivation, on the other hand, can be defined as the desire to take action in order to benefit and contribute to the organizational goals (Davis, Schoorman, \& Donaldson, 1997; Zhang, He, Huang, \& Xie, 2020).

Pro-organizationally motivated employees are more likely to display commitment and dedication to their organization. They are driven by their wish to contribute to organizational success, even when their actions may not promote their own interests. Scholars that studied the "motivation to serve a cause" claim that such motivation is ignited by the desire to make world a better place, as pro-organizational motivation is shaped by enduring values of commitment and dispositions to serve the collective or to serve a common goal (Grant, 2007), representing potential antecedents of pro-organizational motivation. Expectancy and planned behavior theories of motivation (Ajzen, 1991) predict that pro-organizationally motivated workers are more likely to orient their actions to pursue organizational success and to invest time and energy to perform the duties and responsibilities assigned to them. The advocacy of the organizational cause is a strong motivational driver because advancing a shared goal is intrinsically rewarding (Pels, Kleinert, \& Mennigen, 2018; Thompson \& Bunderson, 2003).

Given the assumption that many employees describe the purpose of their work in terms of making a positive difference in others' lives, several scholars pointed to the need, for organizations, to pay attention to factors such as leadership styles, HR strategies and politics, workplace architecture and job design, as means of motivating workers, thereby putting in place the conditions that motivate workers to care for colleagues, customers and the whole organization (Belschak \& Den Hartog, 2010; DeVaro, 2010; Grant, 2007; Tuan, 2017). However, as argued buy job crafting literature, job design is not an exclusive managerial prerogative. Employees also engage, through job crafting behaviors, in a sort of bottom-up, proactive form of autonomous job design. Based on these premises, it seems intuitive to hypothesize that employees may be guided not just by pro-self motivation, but 
also by pro-organizational and pro-social motivation, when they craft their job. In order to explore the soundness of such hypothesis we conducted a qualitative study in a large business organization. In the next paragraph we describe the methodological details and discuss the results.

\section{Methodology}

\subsection{Research Setting}

We conducted a 14 months ethnographic research in which we observed a single group of workers with the same formal job in a large retail company. Being together with the workers for an extended period of time allowed us to observe up close their daily work practices, to understand their points of view and the social meanings given to specific actions and situations (Baba, Gluesing, Ratner, \& Wagner, 2004; Easterby-Smith, Thorpe, \& Lowe, 1991; Weeks, 2000). Also, this approach allowed us to observe how the job crafting process unfolds over time. Finally, the choice of workers at the same formal position multiplied the opportunities to compare job crafting antecedents, practices and outcomes, allowing us to witness the heterogeneity of job crafting dynamics and their evolution even within the same work context with identical formally prescribed tasks and procedures.

Our study was held in one of the largest hyper-stores of THECO (a pseudonym), a large retail company with over 55000 employees, revenues of 12 billion Euros and more than 1500 stores, hyper-stores and super-stores across Europe. In the hyper-store in which our study was conducted (15.000 square meters in size) there are 480 employees in various roles. In the store there are 12 Departments: Fresh Produce, Services, Meat and Fish, Bakery, Gastronomy, General Merchandise, Person and Well-Being, Multimedia, Seasonal, Home, Logistics, Cashiers.

\subsection{Data Collection and Analysis}

The research process was articulated in five main stages.

In the first stage, we conducted a semi-structured, 2 hours long interview with the Human Resources (HR) Manager of the company in order to gather general information about the company and to identify a well suited group of workers in the same formal position that could be observed as potential job crafters. Our goal was to find a specific role with well-defined job descriptions, rules and prescriptions, so that the workers' crafting initiatives could be identified clearly. At the end of this interview, we identified the role of Retail Department Manager (RDM) as the most promising one for the goals of our research. RDMs proved to be ideal subjects for our study, because they represent low-level managerial positions whose activities are very close to all the store's daily operations and tasks, and their formal roles and responsibilities are defined in detail.

The second stage was mostly focused on documents analysis. The goal was to gather detailed information about the company's organization. Researchers had access to the intranet, procedures manuals, organization charts, job descriptions, dictionary of competencies, training programs and performance indicators. This stage allowed researchers to clearly understand the Company's expectations towards the RDMs.

The third stage concerned a semi-structured interview with the Director of the selected store. The goal was to gather detailed information about the features of the store and each of the 4 RDMs on which we focused our study (Meat, General Merchandise, Fresh Produce, Bakery). We inquired about the customers, the competition, economic data, internal organization, and each RDM's specific roles, responsibilities, results, expertise, competencies.

In the fourth stage, we conducted an analysis of the internal documents of the specific Hyperstore. We collected a detailed description of the RDMs' formal tasks. At the end of the fourth stage, a crosschecking of data (Denzin \& Lincoln, 2005; Klein \& Myers, 1999; Yin, 2011) allowed to clearly identify the tasks and goals formally prescribed to the RDMs in that specific context. This represented a continuous reference in order to identify and interpret the job crafting behaviors, thanks to a constant comparison between the formally prescribed behaviors and responsibilities, and the actual observed behavior in the workplace.

In the fifth stage, authors spent about one year in almost continuous observation and interaction with each of the 4 RDMs. In order to provide a higher level of depth to our exploratory and interpretive effort, we alternated open-ended and semi-structured interviews in the RDM's offices, direct observations and informal conversations during work breaks and working hours. This allowed us to develop an "internal perspective" on the work environment and activities (Evered \& Louis, 1981). Interviews and dialogues were structured to elicit detailed descriptions of daily work activities in the workplace. We tried to collect employee's points of view and expectations about their own roles, the meaning that they attribute to them, and how they define themselves at work. We observed and took notice of both RDMs' behavioral choices in the workplace, the meaning and motivations associated to such choices and the contextual elements. 
The constant reference to the job crafting model proposed by Wrzesniewski and Dutton (2001) helped us to formulate the questions asked to the employees. Every time we observed significant changes in the way RDMs experienced their work in terms of i) task boundaries ii) relational boundaries iii) cognitive task boundaries, we tried to identify the antecedents, the contextual elements and variables, the specific and general consequences.

During the analysis, we coded the data along the key themes of the job crafting process. For the whole research period, data collection, coding and analysis proceeded iteratively (Eisenhardt, 1989; Glaser \& Strauss, 1967). In the first step of the analysis, we extracted from our field notes and interview transcripts all the quotes that revealed a change effort by each RDM in relation to their formally prescribed job. Then we split all these codes into three subcategories: change in task boundaries, change in relational boundaries and change in cognitive boundaries. Later, for each RDM and for each job crafting initiative, we coded any accompanying descriptions of the motives that RDMs associated with their behavior. At the same time, we noted both the perceived opportunities that facilitated the job crafting behavior as indicated by the RDMs, and the goals that they associated to their behavior, as well as the outcomes. Such a systematization effort allowed us to clarify the relationship between the contextual elements, the behavior, the meaning, the goals and the outcomes. Finally, consistently with the typical objectives of interpretive research (Langley, 1999; Strauss \& Corbin, 1990) we performed a final analysis of the whole set of data in order to identify common themes among the different RDMs observed.

We adopted an explanation-building technique (Yin, 1994) in order to provide a representation of our research outcomes consistent with the goal of describing how and why job crafting behaviors evolve over time. Thus, for each RDM, we tried to reconstruct individual narratives (Boyce, 1996; Gabriel, 2004; Rhodes \& Brown, 2005) that revealed the most interesting job crafting initiatives and consequent behaviors which, over time, reinforced them. Connecting together actions and events through time and space (Czarniawska-Joerges, 1995) helped us to provide a process view of the observed job crafting behaviors.

\subsection{Narratives}

\subsubsection{Narrative 1: Barry and the Meat \& Fish Department}

The RDM called "Barry" worked for 20 years in the same "Meat and Fish" department. Starting from the lowest employment level, he then became "supervisor" and finally RDM. Barry is one of the very few RDMs that was never assigned to other departments. With some obvious pride, Barry states:

Here, we don't manage stock boys ... you need to know the meats, you need to learn how to cut them, you get dirty with blood, there's a lot of bad smells ... here you need a lot of practice, you need to try and try again ... you know, it takes years to become a butcher ... when you learn how to cut the meat, well, you've learned a job (Barry).

Over time Barry had to face many difficulties:

Once, everything was easier. We knew how to do the job. Then the Company asked all RDMs to decrease personnel costs and to hire un-experienced young people in order to increase the turnover and save on wages ... the directives were very clear: we had to attribute qualified tasks to experienced people and simple tasks to young people. We could save money and we didn't waste time in training the young ... well, I don't know about the others [Departments], but we've always set up an intense training for our newcomers in this Department, because we want to teach them the job. I personally put a lot of effort, together with my collaborators, to do it ... I "grew up" here and I don't care if I have to get my hands dirty ... the Company didn't ask me to do it, but I always worked hard to train our kids ... we even asked to do overtime hours so that we could train them. We have to teach, just like the older ones taught us in the past; in this Department you cannot just check costs and revenues ... you have to "transfer" a job [a skill] ... also, if a young kid asks you questions and shows interest, you know, that is satisfying for me ... people here are getting older and I don't want to find myself in a few years having to manage a bunch of novices ... Sure, it takes some time, but this saved us when two seniors retired ... also, you know, I need to be careful. It's better to work with people that you know how they work (Barry).

Barry decided to structure his (and his collaborators') activities differently from what was prescribed by his formal role, by adding new tasks in order to provide training to his younger collaborators. However, at some point, things changed quickly:

This year there are new cost cuts and the overtime work is no longer enough to train the boys and achieve my objectives at the same time ... but we don't give up: we like to dedicate time to the boys, and this proved time and time again to be a winning strategy. So, I tried to group tasks together according to different kinds of activities, and I gave each senior worker the responsibility of one group. Then I assigned the novices to different groups, considering both the length of each activity and the 
length of each work shift. Every novice works his shift in two different groups until he learns, then he switches to another group ... this way he can experience quickly the whole process. I repeat, if I didn't have a lot of experience and if I didn't know exactly all kinds of meat cuts, I couldn't even try this thing ... I can't deny it, this is still an experiment ... but if I want to achieve the department goals and leave [to the young] something of us [our knowledge], with the limited resources I have, well, this is what I can do ... maybe in the future things will change ... but we're confident, we know our stuff here ... we've always achieved good results ... and that's why the Management doesn't really bother us, in this Department .. you know, we have the best results of all "Meat and Fish" Departments of all stores in the nation, here! (Barry).

This is a case where practically all the elements of the original job crafting model by Wrzesniewski and Dutton (2001) are clearly present. First, Barry altered the nature and number of his tasks by adding a significant emphasis on training activities, which are not prescribed by his formal role. Second, he changed the relational boundaries by setting new work organization arrangements in order to increase the interactions between novices and senior workers, for training purposes (the creation of work groups and the rotation of novices among them). This is not only un-prescribed, it obviously goes against the company's formal prescriptions, according to which there should be a clear separation of tasks between senior and young workers. Finally, Barry also changed the cognitive boundary of his job, when he envisions his goal and priority not just in terms of the economic results of his department (e.g, cutting costs), but also in terms of the responsibility of ensuring long term effectiveness of the department thanks to the intergenerational transfer of knowledge and skills.

What are the motivations that explain Barry's behavior? Certainly, as predicted by the job crafting model, there is a need for "control" and "positive self-image" in Barry's pro-self motivations. Barry's training effort can be seen as a way to make sure that novices work the way he wants, and this may improve his ability to control the work process. That's what Barry seems to suggest when he says "I need to be careful ... You know, it's better to work with people that you know how they work". Also, Barry seems to be motivated by being publicly recognized both as someone teaching the young a "real job", and as an RDM with the best results in the country. Thus, positive self-image seems to be a major motivation. Also, the "human connection" motivation seems to be relevant, as Barry clearly declares that he's happy and satisfied when young people show interest and ask questions.

There is another motivational element, however, that the job crafting model does not seem to consider. Current job crafting theory is mostly focused on individual goals and pro-self motivations. In Barry's case, however, it seems clear that the problem of ensuring good organizational results for the long term plays a key role in his motivations. Transferring knowledge and skills to the novices is the solution that Barry found and implemented. It seems that the Company neglected or even ignored the relevance of such a problem, as no intergenerational knowledge transfer program was established. On the contrary, the Company required seniors and novices to perform different tasks separately (simple tasks for novices, complex tasks for seniors) without worrying about the negative consequences of retiring seniors, a problem that, instead, Barry clearly anticipates. Thus, Barry "sees" an organizational problem that the Company does not recognize. He takes charge of the problem, he "internalizes" it, and he tries to find a solution by crafting his job. It is also very important to notice that this is not contradictory with his pro-self motivations. Instead, pro-self and pro-organizational motivations seem to converge and reinforce each other.

Also, a clear pro-social motivational element is present in Barry's behaviors, as he cares about training the young employees. He says: "We have to teach, just like the older ones taught us in the past ... you have to "transfer" a job [a skill]". Barry seems to care about the professional future of the young employees, and teaching them how to be skilled butchers, not just in relation to simple tasks, as the Company asked, is truly important to him. It is also interesting to notice that such a pro-social motivation seems to converge perfectly with his pro-self motivation, as perpetuating an old, traditional job (the butcher) is something that he deeply, personally cares about.

Barry repeatedly emphasizes that much of what he does (by crafting his job) is possible because of his long and in-depth experience, down to the technical aspects of each single manual operation (e.g., cutting meats). That's a key condition that explains why he was able to set up a sort of "informal" training program for the novices without disrupting the Department's workflow. Without such an experience, he could not even imagine these practices. Thus, this case shows that experience may play a relevant role in explaining job crafting behaviors. This is not to say that un-experienced employees do not have the ability to engage in job crafting practices. As we will show in other narratives, sometimes a lack of experience appears to be significant, in a different way, for job crafting. 


\subsubsection{Narrative 2: Gilbert and the General Merchandise Department}

Gilbert has been the RDM of the "General Merchandise Department" for many years.

This is a peculiar department, more complex than it seems. They think I'm just the head of a bunch of stock boys, and they say that I have to do nothing but to follow the procedures, but it's not that simple ... This is one of the largest departments - there are over 70 people working here - and we have many activities ... also, we have the responsibility to choose the supplies. This is a very important thing, and the income of the department depends on that (Gilbert).

Indeed, the management of supplies is critical, and the Company has been trying to standardize such activity for a long time.

It is hard to choose the right number and type of products to purchase ... if one day I don't have a certain product on the shelves, the profitability of the department could decrease a lot. It takes a certain level of experience to know what products and how many you are going to sell ... Last year, the Company adopted an automatic purchasing system. The buying order is computer-generated every evening, depending on the sales. Now, we are just asked to approve the order and send it to corporate. And that's what we did, for a while. The system ensures a good "coverage", but sometimes we don't have enough products ... this should never happen for those products that we know are important for our customers, otherwise they [the customers] leave the store complaining ... But the system treats all products in the same way. Well, I decided to go back to the old system, even if I wasn't allowed to do it. Basically we put together the order manually, each of us for his own aisle, then we compare it with the automatic order, which we modify according to our judgment ... yes, it takes time, but I feel more confident this way because I can anticipate problems ... and, besides, what would other departments say of us [if we didn't do this]? They'd say that we are just a bunch of stock boys! (Gilbert).

Gilbert tried to explain the problem to the store's Director, but he was not allowed to change the formal procedure:

I tried to tell the Director, to show him ... but the procedure stayed the same. So, I decided to do it my way anyway. You know, in the end I am responsible for the results. If things don't work well, they're going to blame me because I didn't follow the procedure. But things do work better this way (Gilbert).

Gilbert's story represents another case that seems to fit the job crafting theoretical model quite nicely. The way Gilbert crafted his job could be interpreted as a way to resist changes demanded by the management. Gilbert crafts his coordination task in order to go back to the "old" arrangements, which, according to his judgment, are more effective and less risky than the new ones. His relational activities and boundaries are also changed, as new types of interactions with his collaborators allow him to "fix" the purchasing order generated by the automatic system. Even the cognitive task boundaries are modified, as Gilbert explains how his activities are oriented toward the long term satisfaction of customers, not just the short term economic results of the Department.

The job crafting theoretical model allows to identify Gilbert's motivations. The need for control seems to be part of the reasons why Gilbert refuses to give up his purchasing responsibility. The need for positive self-image seems obvious when he insists on saying that he doesn't want to be seen as "the manager of a bunch of stock boys". He wants to be recognized as a "real manager", and the automated procedure threatens to impoverish his public image as a decision maker.

While these pro-self motivations explain some of Gilbert's reasons for his job crafting initiatives, however we should consider organizational problem-solving as a relevant motivation as well. Gilbert is honestly concerned that the automated purchasing system will create difficulties with some "key products", the ones that he knows the Company cannot afford not to have on the shelves. He knows that the automated software does not differentiate products in relation to how "important" they are for the customers, and this is, according to his judgment, a faulty approach. Thus, again, it is hard to dismiss the fact that Gilbert, just like Barry, "sees" a potential organizational problem and figures out a way to solve it by crafting his job. The consistency between pro-self and pro-organizational motivations enhances his "drive" to engage in job crafting activities. Experience also plays a major role. Without his long experience about customer's preferences and behaviors (reinforced by his own past mistakes about what products to order), Gilbert would not be able to see the possible "dangers" that the automatic system creates, and also - most of all - he could not imagine an alternative method. As far as the role of experience is concerned, Gilbert's story offers an account similar to Barry's. We will see in the next two paragraphs that experience can play a relevant role in other, different ways.

\subsubsection{Narrative 3: Claudine and the Fresh Produce Department}

Claudine has been RDM of the Fresh Produce (Fruit and Vegetable) Department for only 1 year, but in her career as RDM she worked in many other departments. 
In 10 years I've changed so many departments, I did them all, food, no food ... these are all very different departments, but I've always been at ease ... I love this job, and the part that I love the most is staying in touch with people, talking to them, relating to them (Claudine).

According to Claudine, the "secret" of her excellent performance is the close, friendly relationship that she is able to build with her collaborators. She puts a lot of effort towards that goal.

I don't care about the way a RDM is supposed to interact with her collaborators, according to the Company. I just stay with them in the Department ... I study them, I watch them, and then I try to get closer to them ... but in order to do that you have to build a trust relationship. You have to spend a lot of time with them, you can't just stay in your office all the time (Claudine).

Consistently with job crafting theory, Claudine altered the relational boundaries of her job in order to include frequent interactions with her collaborators.

I realized that you have to learn to trust your collaborators. In your career you may change departments so often that you don't have time to learn all the specific techniques of each department. Your collaborators know so much about the products, and you just don't have time to learn so much in a short period of time, so, after you have built a solid relationship, you have to delegate to them the tasks that they can accomplish better than yourself ... For example, in this Department I don't take care of purchases anymore. I know I shouldn't ignore this completely, but the truth is that I understand nothing about fruit and vegetables, and now I just can trust my collaborators' judgments (Claudine).

The way Claudine acts as a job crafter is very peculiar. She doesn't increase the number of her tasks, as Barry and Gilbert did. Instead, she changes them. She completely decentralizes any product-related decision to her collaborators, including the purchasing decisions - the same decisions that were so crucial for Gilbert. When compared to other RDMs, Claudine spends much more time down in the store than in her office. She devotes a great deal of effort by talking and establishing a personal relationship with each of her collaborators. Thus, she deeply re-shapes the nature of her tasks, as well as the nature of her social relations.

The need for "human connection" seems to be Claudine's dominant motivation for job crafting. The need for a "positive self-image" is also relevant. She is motivated to maintain her reputation as a top performer, and the way she crafts her job allows her to do just that. Indeed, Claudine believes that her managerial style is particularly effective in "new" situations. When she arrives in a new Department, knowing that most likely the Company might move her to another one in a relatively short period of time, she realizes that she would waste a lot of time by trying to learn all the technical details of the Department's activities. She found that a much more effective solution is to delegate and, at the same time, to build trust with her collaborators in order to acquire their flexibility and commitment. Far from being just self-motivated by the need for human connection or self-image, for Claudine - just like Barry and Gilbert - the need to solve her managerial problem appears to have a significant influence. The organizational motivation converges, once again, with the pro-self one. Her organizationally effective coordination style is especially very consistent with her strong need for human connection and her need for a positive self-image

Experience also seems to be, again, a crucial variable. However, in this case experience has an influence in two different ways at two different levels of analysis. At a more general level, Claudine's extensive experience as RDM allows her to identify an effective coordination approach. On a more operational level, instead, her lack of technical experience and knowledge about the Department's products is exactly what pushes her to craft her job by delegating specific decisions. We clearly see a "dual" effect of experience on job crafting behaviors. Indeed, Claudine's example shows that experience may affect job crafting in a way that seems to be relevant both when the "amount" of experience is "high", and / or when it is "low". In this case, we see the two effects taking place at the same time, simply because they refer to different kinds of experience and knowledge. Her high level of managerial experience allows Claudine to successfully change her general approach to coordination (just like in the case of Barry and Gilbert). However, her low level of products' knowledge is exactly what pushes her to delegate some decisions and to seek help from her collaborators - in other words, by focusing on a type of job crafting in which the relational / social aspect is the most significant. Thus, experience (high or low level respectively) influences both her ability to identify an opportunity to craft her job and her decision about what specific kind of job crafting behavior (a socially-oriented one) to enact.

\subsubsection{Narrative 4: George and the Bakery Department}

George developed a multi-year experience as RDM, with excellent results.

I coordinated several Departments. At the beginning of this year they gave me the Bakery Department. Here the products are prepared by more than 20 cooks, bakers and pastry chefs. Hence, a lot of diverse activities have to be performed, it's not just about people filling up the shelves and checking the 
numbers ... very highly skilled people work here (George).

George realizes quickly that managing a Department like this is quite complicated.

At the beginning I tried to manage this Department as I've always done, which is by using the managerial competencies that the Company gave us in training. But soon I realized that here, if you don't know exactly what people do and how they do it, you're not going anywhere ... besides, I don't like to depend too much on others (George).

George feels that he does not possess enough technical knowledge about the Bakery's activity in order to be a good RDM. This became a real issue for him when a serious problem with one of his workers happened. The problem concerned the assessment of workers. The Company requires that RDMs do not assess directly the workers, but delegate such a task to intermediate collaborators. George, however, does not like such an approach.

At the end of the year, we had to assess the personnel. It's ok to trust your collaborators to assign little prizes and perks, but this year I had to make a very important decision. I had to decide whether to fire an employee because, according to some of my intermediate collaborators, she wasn't performing well enough. This became a problem for me because I didn't have the technical knowledge to really evaluate this girl. And I couldn't make such a relevant decision just by trusting what others said because it's an ethical issue. But, on the other side, if I didn't fire her, I would have created a strong sense of unfairness among her colleagues. So, in the end, I had to fire her, but at that point I promised myself to learn as much as I could about what people do here ... So, I decided to devote part of my work day to closely follow everything that happens, to learn very well what everybody does and how, instead of staying isolated in my office. After all, this is not wasted time, because this allows me to do my job much better ... I know this is not what the Company expects me to do, but I don't want to find myself in the same situation again (George).

There are obviously a number of job crafting practices in George's case. First, he does not want to delegate to his intermediate collaborators the task of assessing the lower level workers. Second, he spends part of his time trying to learn the technicalities of the Bakery's activities by working together with the operators. All these activities are neither prescribed by the formal rules of the Company, nor what George used to do when he worked as RDM in other Departments. For the same reason, the relational boundaries are dramatically changed as well. Even from a cognitive point of view, we can observe that George, once faced with his sudden dilemma, changed his understanding about his own job. He now believes that being an RDM is not just about obtaining good results, but it is also about being fair and just. In terms of motivations, we find here a significant "need for control", because his unwillingness to delegate is probably related to it. There is also a strong need for a "positive self-image", as he is worried to appear fair to others. However, even in George's case, the organizational problem solving motivation appears to be quite significant. His problem is to evaluate correctly his collaborators. In this respect, there are interesting differences with other cases. In Barry's and Gilbert's cases, the organizational problem was identified by Barry and Gilbert themselves, not by the Company. They "discovered" problems that the Company ignored. In George's case, instead, the responsibility of a certain problem-solving task (assessing the employees) is defined and attributed by the Company itself. The Company also identifies a specific solution to such problem (to delegate the assessment task to intermediate collaborators). But George doesn't like such a solution, so he crafts his job in order to find a better one that is also consistent with his pro-self motivations. In fact, the convergence of the two types of motivations (pro-organizational and pro-self) creates a very powerful drive to craft his job.

There is also another interesting difference. While Claudine responded to her lack of technical knowledge by delegating decisions, George wants to avoid delegating (even though that's what the Company expects from him) and, in order to do so, he crafts his job in order to acquire the knowledge that would allow him to perform the employee assessment himself. Again, we see that experience plays a relevant role. George's experience helps him to realize that he needs to craft his job in order to achieve the desired level of fairness. However, his lack of technical knowledge is what pushed him to pursue a specific kind of job crafting (a socially-oriented one) - that is, to increase the opportunities to interact with his collaborators in the bakery.

\section{Discussion}

Our research has brought us to question the idea that employees craft their jobs only because of pro-self goals and motivations. We found that, in most cases, job crafters are driven by a combination of pro-self, pro-social and pro-organizational motivations. When these motivations converge, their effect on employee's propensity to craft their jobs becomes stronger. 
This result seems consistent with what reported by Batova (2018). Through a 12-month qualitative study, the author found that technical communicators crafted their job in different ways in order to improve their ability to control their work, to improve their self-image and, at the same time, to provide a better service to their customers. Based on such evidence Batova (2018) argued that both pro-social motivation and intrinsic motivation may help explaining the way job crafters chose to re-design their job in order improve its meaning, with positive consequences for performance and productivity.

How can pro-social, pro-organizational and pro-self motivations coexist? While it may seem counterintuitive, a number of scholars showed that these motivations do not necessarily contradict each other (Curry et al., 2018), but instead they seem to work independently (Bolino, 1999; Grant, 2009). Shamir (1990) argued that "many organizationally relevant actions are probably performed both for a person's own sake and for the sake of a collectivity such as a team, department, or organization [...] with a wide range of motivational orientations that are neither purely individualistic [...] nor purely altruistic" (Shamir, 1990). Several empirical studies found evidence of such possibility (De Dreu \& Nauta, 2009; McAdams \& de St. Aubin, 1992; Sheldon, Arndt, \& Houser-Marko, 2003). Thus, it seems reasonable that a convergence between pro-self, pro-social and pro-organizational motivations represents a relevant antecedent of job crafting behaviors. Such convergence is likely to be the outcome of a creative, interpretive process enacted over time by individuals. Sometimes employees look for and/or discover "hidden" problems that the managerial hierarchy cannot or does not see, so they craft their jobs in order to find a solution (like Barry and George in our study). In other cases, employees "appropriate" explicit organizational problems and craft their jobs in order to change the company's approach to them (like Gilbert and Claudine in our study). In all cases, subjects play a clear agentic role in cognitively constructing such a convergence.

It is also worth noticing that pro-social and pro-organizational motivation are not necessarily ignited by altruism alone. Batson and colleagues (2008) proposed that pro-social motivation can be based on general goals such as "altruism" (to benefit others), "egotism" (to benefit self), "principlism" (to advance moral or ethical causes) or "collectivism" (to benefit a group), or any combination of them. Thus, with the exception of extreme cases in which the motivation for job crafting is based solely on egotism, in all other cases it is likely that we will observe a combination of altruism, principlism and collectivism. This is clearly observable in our 4 examples. Barry's focus on training the novices is clearly related to a collectivistic (the long-term effectiveness of his Department) and principlistic goals (to perpetuate the "butcher tradition"); Gilbert's efforts about the purchasing activity are based on collectivistic goals (to ensure customers' satisfaction and, by consequence, the organizational performance); Claudine's approach to managing her Department is also based on collectivistic goals (to manage the Department effectively), while George's approach to personnel assessment is clearly related to principlism (his ethical view of management) and also altruism (his desire that his collaborators are evaluated fairly).

The joint effect of pro-self, pro-social and pro-organizational motivations on job crafting can be quite powerful not only because of the intrinsic strength of pro-social and pro-organizational motivations, but also because the presence of organizational goals may help employees to acquire legitimation among colleagues and supervisors for their proactive, "crafted" behaviors. Indeed, Grant et al. (2009) argued that supervisors assess proactive employees more favorably when the latter show pro-social behaviors. More generally, the presence of organizational goals in job crafting behaviors may be not only the effect of genuine pro-social and pro-organizational motivations, but can also represent, at the same time, an "adaptive move" in order to facilitate and legitimize job crafting, as described by Berg, Wrzesniewski, and Dutton (2010). This claim does not contradict the relevance of organizationally-oriented goals. Indeed, it is worth noting that Berg, Wrzesniewski, et al. (2010) focused on problem solving in terms of the individual challenges that employees have to face in order to craft their jobs, not on organizational problem solving as a motivational driver in itself. Thus, our thesis seems to be complementary to that of Berg, Wrzesniewski, et al. (2010). The strength of organizational goals stems from both their function as "adaptive moves" that facilitate job crafting, and their intrinsic motivational value.

Overall, it seems that a clear-cut, static separation between what is pro-self and what is pro-organizational and pro-social does not make justice of a much more intricate interpretive, sense-making process in which employees engage while reflecting about how to behave in their workplace.

Work experience also helps to achieve a deeper understanding of how different motivations interact in relation to job crafting. Some authors argue that a higher level of experience, but increasing knowledge and awareness of work processes, and self-efficacy, may increase job crafting opportunities. By focusing on pro-organizational motivation we found that experience functions as a "tool" through which employees become better at identifying specific job crafting opportunities, the ones where pro-self and pro-organizational motivations converge. Generally, experienced workers are better able than novices to understand their work process and its relationship 
with the organizational context. Hence, it will be easier for them to identify interesting job crafting opportunities where different motivations converge. In other words, higher levels of experience should enable employees to find not just "more" but also "better" (more likely to be accepted, and more likely to be successful) opportunities to craft their jobs.

Also, our results show that a low level of experience might also be related to job crafting in interesting ways. This may happen when employees see job crafting as a learning opportunity through which they can satisfy their pro-self and pro-organizational goals.

We argue that inexperienced employees may be more likely to craft their job specifically by trying to increase their social job resources, such as social support, supervisory coaching, feedbacks, and all other resources requiring the enactment of social interactions in the workplace. Both Claudine's and George's stories provide good examples. George's lack of knowledge about the bakery's work processes drove him to craft his job by increasing the opportunities for his social interactions with his collaborators in the workshop. Claudine crafted her job by delegating some of her decision making tasks to her more experienced collaborators and, at the same time, by increasing her social interactions with them in order to build trust and reciprocity.

\section{Final Remarks, Limitations and Future Research Opportunities}

We agree with Berg and colleagues when they claim that "job crafting is more complex than previously suggested by the job crafting literature" (Berg et al., 2010, p. 160). We believe that such complexity probably concerns, at least in part, the set of motivations and reasons explaining why people craft their jobs. We argue that job crafting cannot be fully understood in terms of pro-self motivations alone. Indeed, the interplay between different motivations may be crucial for a more accurate account of job crafting. Also, we believe that work experience plays a key role in identifying both how likely it is to observe job crafting, and what specific kind of job crafting behavior will be initiated. Our empirical research, thanks to a longitudinal, qualitative approach, allowed us to unveil some of the job crafting complexities and also suggested possible theoretical interpretations. However, the most obvious limitation of our study is the small sample size and the limited variety of the subjects that we observed. We hope that future studies will be able to test the general validity of our results. This could be done in various ways. First, our study could be replicated through a similar qualitative, longitudinal approach in other organizations, in other industries and with a larger number of observations. It is quite obvious, indeed, that our results may somewhat vary depending on the specific work context. However, we suspect that our findings have a general quality; while different organizational cultures will surely lead to somewhat different outcomes and nuances, we believe that the fundamental aspects of our results should hold well across a large variety of organizational situations. Obviously, only future research may either validate or reject our claim. Also, we believe that our findings could be tested empirically through statistical methods. Validated scales are already available to measure all the relevant variables that we discussed in this paper. Integrating qualitative and quantitative results might be a productive way to advance our knowledge about job crafting and proactivity in the workplace.

\section{References}

Ajzen, I. (1991). The theory of planned behavior. Organizational Behavior and Human Decision Processes, 50(2), 179-211. https://doi.org/10.1016/0749-5978(91)90020-T

Baba, M. L., Gluesing, J., Ratner, H., \& Wagner, K. H. (2004). The Contexts of Knowing: Natural History of a Globally Distributed Team. Journal of Organizational Behavior, 25(5), 547-587. https://doi.org/10.1002/job.259

Bakker, A. B., Tims, M., \& Derks, D. (2012). Proactive personality and job performance: The role of job crafting and work engagement. Human Relations, 65(10), 1359-1378. https://doi.org/10.1177/0018726712453471

Batova, T. (2018). Work Motivation in the Rhetoric of Component Content Management. Journal of Business and Technical Communication, 32(3), 308-346. https://doi.org/10.1177/1050651918762030

Batson, C. D., Ahmad, N., Powell, A. A., \& Stocks, E. L. (2008). Prosocial motivation. In Y. Shah \& W. L. Gardner (Eds.), Handbook of motivation science (pp. 135-149). New York: Guilford Press.

Belschak, F. D., \& Den Hartog, D. N. (2010). Pro-self, prosocial, and pro-organizational foci of proactive behaviour: Differential antecedents and consequences. Journal of Occupational and Organizational Psychology, 83(2), 475-498. https://doi.org/10.1348/096317909x439208

Berg, J. M., Wrzesniewski, A., \& Dutton, J. E. (2010). Perceiving and responding to challenges in job crafting at different ranks: When proactivity requires adaptivity. Journal of Organizational Behavior, 31(2-3), 158-186. 
https://doi.org/10.1002/job.645

Bolino, M. C. (1999). Citizenship and impression management: Good soldiers or good actors? Academy of Management Review, 24(1), 82-98. https://doi.org/10.2307/259038

Boyce, M. E. (1996). Organizational story and storytelling: A critical review. Journal of Organizational Change Management, 9(5), 5-26. https://doi.org/10.1108/09534819610128760

Curry, O. S., Rowland, L. A., Van Lissa, C. J., Zlotowitz, S., McAlaney, J., \& Whitehouse, H. (2018). Happy to help? A systematic review and meta-analysis of the effects of performing acts of kindness on the well-being of the actor. Journal of Experimental Social Psychology, 76, 320-329. https://doi.org/10.1016/j.jesp.2018.02.014

Czarniawska-Joerges, B. (1995). Narration or science? Collapsing the division in organization studies. Organization, 2(1), 11-33. https://doi.org/10.1177/135050849521002

Davis, J. H., Schoorman, F. D., \& Donaldson, L. (1997). Toward a Stewardship Theory of Management. The Academy of Management Review, 22(1), 20-47. https://doi.org/10.2307/259223

De Dreu, C. K. W., \& Nauta, A. (2009). Self-interest and other-orientation in organizational behavior: Implications for job performance, prosocial behavior, and personal initiative. Journal of Applied Psychology, 94(4), 913-926. https://doi.org/10.1037/a0014494

Denzin, N., \& Lincoln, Y. (2005). The SAGE Handbook of Qualitative Research (3rd ed.). Thousand Oaks, CA: Sage.

DeVaro, J. (2010). A theoretical analysis of relational job design and compensation. Journal of Organizational Behavior, 31(2-3), 279-301. https://doi.org/10.1002/job.596

Easterby-Smith, M., Thorpe, R., \& Lowe, A. (1991). Management research. London: Sage.

Eisenhardt, K. M. (1989). Building theories from case study research. Academy of Management Review, 14(4), 532-550. https://doi.org/10.2307/258557

Emery, F. E., \& Trist, E. L. (1960). Socio-technical Systems. In C. W. Churchman \& M. Verhulst (Eds.), Management Science. Oxford: Pergamon.

Evered, R., \& Louis, M. (1981). Alternative perspectives in the organizational sciences: "inquiry from the inside" and "inquiry from the outside". Academy of Management Reviews, 6(3), 385-396. https://doi.org/10.5465/amr.1981.4285776

Frese, M., Kring, W., Soose, A., \& Zempel, J. (1996). Personal initiative at work: Differences between East and West Germany. Academy of Management Journal, 39, 37-63. https://doi.org/10.5465/256630

Gabriel, Y. (2004). The Narrative Veil: Truth and Untruths in Storytelling. In Y. Gabriel (Ed.), Myths, Stories and Organizations: Premodern Narratives for Our Times (pp. 17-31). Oxford: Oxford University Press.

Glaser, B. G., \& Strauss, A. L. (1967). The Discovery of Grounded Theory: Strategies for Qualitative Research. Chicago: Aldine Publishing Company.

Graen, G. B., \& Scandura, T. A. (1987). Toward a psychology of dyadic organizing. Research in Organizational Behavior, 9, 175-208.

Grant, A. M. (2007). Relational job design and the motivation to make a prosocial difference. Academy of Management. The Academy of Management Review, 32(2), 393-417. https://doi.org/10.2307/20159308

Grant, A. M. (2009). Putting self-interest out of business? Contributions and unanswered questions from use-inspired research on prosocial motivation. Industrial and Organizational Psychology, 2(1), 94-98. https://doi.org/10.1111/j.1754-9434.2008.01113.x

Grant, A. M., \& Ashford, S. J. (2008). The dynamics of proactivity at work. Research in Organizational Behavior, 28, 3-34. https://doi.org/10.1016/j.riob.2008.04.002

Grant, A. M., Parker, S. K., \& Collins, C. G. (2009). Getting credit for proactive behavior: Supervisor reactions depend on what you value and how you feel. Personnel Psychology, 62(1), 31-55. https://doi.org/10.1111/j.1744-6570.2008.01128.x

Hackman, J. R., \& Oldham, G. R. (1980). Work Redesign. Reading, MA: Addison-Wesley.

Klein, H. K., \& Myers, M. D. (1999). A Set of Principles for Conducting and Evaluating Interpretive Field Studies in Information Systems. MIS Quarterly, 23(1), 67-69. https://doi.org/10.2307/249410 
Langley, A. (1999). Strategies for theorizing from process data. Academy of Management Review, 24(4), 691710. https://doi.org/10.5465/amr.1999.2553248

Laurence, G. A., Fried, Y., Yan, W., \& Li, J. (2020). Enjoyment of work, as an intrinsic motivation: Evidence from Japan and China. Japanese Psychological Research, 62(1), 1-13. https://doi.org/10.1111/jpr.12239

Lazazzara, A., Tims, M., \& de Gennaro, D. (2020). The process of reinventing a job: A meta-synthesis of qualitative job crafting research. Journal of Vocational Behavior, 116. https://doi.org/10.1016/j.jvb.2019.01.001

Letona-Ibanez, O., Carrasco, M., Martinez-Rodriguez, S., Amillano, A., \& Ortiz-Marques, N. (2019). Cognitive, relational and task crafting: Spanish adaptation and analysis of psychometric properties of the Job Crafting Questionnaire. PLoS One, 14(10), 1-15. https://doi.org/10.1371/journal.pone.0223539

Lu, C.-q., Wang, H.-j., Lu, J.-j., Du, D.-y., \& Bakker, A. B. (2014). Does work engagement increase person-job fit? The role of job crafting and job insecurity. Journal of Vocational Behavior, 84(2), 142-152. https://doi.org/10.1016/j.jvb.2013.12.004

Maslow, A. H. (1954). Motivation and Personality. New York: Harper \& Row.

McAdams, D. P., \& de St. Aubin, E. (1992). A theory of generativity and its assessment through self-report, behavioral acts, and narrative themes in autobiography. Journal of Personality and Social Psychology, 62, 1003-1015. https://doi.org/10.1037/0022-3514.62.6.1003

McClelland, D. C. (1971). Assessing Human Motivations. New York: General Learngin Press.

Moon, T., Youn, N., Hur, W.-M., \& Kim, K.-M. (2018). Does employees' spirituality enhance job performance? The mediating roles of intrinsic motivation and job crafting. Current Psychology, 1-17. https://doi.org/10.1007/s12144-018-9864-0

Nicholson, N. (2010). The design of work - an evolutionary perspective. Journal of Organizational Behavior, 31(2/3), 422-431. doi: 10.1002/job

Niessen, C., Weseler, D., \& Kostova, P. (2016). When and why do individuals craft their jobs? The role of individual motivation and work characteristics for job crafting. Human Relations, 69(6), 1287-1313. https://doi.org/10.1177/0018726715610642

Organ, D. W. (1997). Organizational citizenship behavior: It's construct clean-up time. Human Performance, 10(2), 85-97. https://doi.org/10.1207/s15327043hup1002_2

Pasmore, W. A. (1995). Social-Science Transformed - the Sociotechnical Perspective. Human Relations, 48(1), $1-21$.

Pels, F., Kleinert, J., \& Mennigen, F. (2018). Group flow: A scoping review of definitions, theoretical approaches, measures and findings. PLoS One, 13(12). https://doi.org/10.1371/journal.pone.0210117

Rhodes, C., \& Brown, A. D. (2005). Narrative, organizations and research. International Journal of Management Reviews, 7(3), 167-188. doi: 10.1111/j.1468-2370.2005.00112.x

Rudolph, C. W., Katz, I. M., Lavigne, K. N., \& Zacher, H. (2017). Job crafting: A meta-analysis of relationships with individual differences, job characteristics, and work outcomes. Journal of Vocational Behavior, 102, 112-138. https://doi.org/10.1016/j.jvb.2017.05.008

Schein, E. H. (1971). Occupational socialization in the professions: The case of role innovation. Journal of Psychiatric Research, 8, 521-530. https://doi.org/10.1016/0022-3956(71)90041-0

Shamir, B. (1990). Calculations, Values, and Identities: The Sources of Collectivistic Work Motivation. Human Relations, 43(4), 313-332. https://doi.org/10.1177/001872679004300402

Sheldon, K. M., Arndt, J., \& Houser-Marko, L. (2003). In search of the organismic valuing process: The human tendency to move towards beneficial goal choices. Journal of Personality, 71(5), 835-869. https://doi.org/10.1111/1467-6494.7105006

Shin, I., \& Jung, H. (2019). Differential roles of self-determined motivations in describing job crafting behavior and organizational change commitment. Current Psychology. https://doi.org/10.1007/s12144-019-00265-2

Staw, B. M., \& Boettger, R. D. (1990). Task Revision - a Neglected Form of Work Performance. Academy of Management Journal, 33(3), 534-559. https://doi.org/10.5465/256580

Strauss, A., \& Corbin, J. (1990). Basics of qualitative research: Grounded theory procedures and techniques. 
London: Sage.

Thompson, J. A., \& Bunderson, J. S. (2003). Violations of Principle: Ideological Currency in the Psychological Contract. The Academy of Management Review, 28(4), 571-586. https://doi.org/10.2307/30040748

Tims, M., \& Bakker, A. B. (2010). Job crafting: Towards a new model of individual job redesign. South African Journal of Industrial Psychology, 36(2), 1-9. https://doi.org/ 10.4102/sajip.v36i2.841

Tims, M., Bakker, A. B., \& Derks, D. (2012). Development and validation of the job crafting scale. Journal of Vocational Behavior, 80(1), 173-186. https://doi.org/10.1016/j.jvb.2011.05.009

Tims, M., Bakker, A. B., \& Derks, D. A. (2013). The Impact of Job Crafting on Job Demands, Job Resources, and Well-Being. Journal of Occupational Health Psychology, 18(2), 230-240. https://doi.org/10.1037/a0032141

Tjosvold, D., Wong, A. S. H., \& Feng Chen, N Y. (2014). Constructively Managing Conflicts in Organizations. Annual Review of Organizational Psychology and Organizational Behavior, 1(1), 545-568. https://doi.org/10.1146/annurev-orgpsych-031413-091306

Tuan, L. T. (2017). HR Flexibility and Job Crafting in Public Organizations: The Roles of Knowledge Sharing and Public Service Motivation. Group \& Organization Management, 44(3), 549-577. https://doi.org/10.1177/1059601117741818

Vroom, V. H. (1964). Work and Motivation. New York: WIley.

Weeks, J. R. (2000). What do ethnographers believe? Human Relations, 53, 153-171. https://doi.org/10.1177/0018726700531007

Wrzesniewski, A., \& Dutton, J. E. (2001). Crafting a Job: Revisioning Employees as Active Crafters of Their Work. Academy of Management Review, 26(2), 179-201. https://doi.org/10.2307/259118

Yin, R K. (2017). Case study research and applications: Design and methods (6th ed.). Thousand Oaks, CA: Sage.

Yin, R. K. (1994). Case Study Research, Design and methods (2th ed.). Beverly Hills, CA: Sage.

Yin, R. K. (2011). Qualitative research from start to finish. New York, NY: Guilford.

Yitzhak, F., Grant, A. M., Levi, A. S., Hadani, M., \& Haynes Slowick, L. (2007). Job design in temporal context: a career dynamics perspective. Journal of Organizational Behavior, 28(7), 911. https://doi.org/10.1002/job.486

Zhang, F., \& Parker, S. K. (2019). Reorienting job crafting research: A hierarchical structure of job crafting concepts and integrative review. Journal of Organizational Behavior, 40(2), 126-146. https://doi.org/10.1002/job.2332

Zhang, Yun, He, Bin, Huang, Qihai, \& Xie, Jun. (2020). Effects of supervisor bottom-line mentality on subordinate unethical pro-organizational behavior. Journal of Managerial Psychology. https://doi.org/10.1108/jmp-11-2018-0492

\section{Copyrights}

Copyright for this article is retained by the author(s), with first publication rights granted to the journal.

This is an open-access article distributed under the terms and conditions of the Creative Commons Attribution license (http://creativecommons.org/licenses/by/4.0/). 